\title{
AJUSTE DE UN MODELO RASCH MULTIDIMENSIONAL AL CUESTIONARIO DE LAS CINCO FACETAS DE CONCIENCIA PLENA (FFMQ) APLICADO A PRACTICANTES DE YOGA
}

\author{
Andrés Alberto Burga León \\ https://orcid.org/0000-0003-0388-4238 \\ Oficina de Medición de la Calidad \\ de los Aprendizajes (UMC), \\ Ministerio de Educación del Perú
}

\author{
RAfFaElla PAPI MARIÁtEguI \\ Artibus - Centro Especializado \\ en Neuropsicología y Aprendizaje
}

Recibido: 10 de abril del 2019 / Aceptado: 12 de junio del 2019 doi: 10.26439/persona2019.n022(2).4562

\begin{abstract}
Resumen. Los objetivos planteados para la presente investigación son obtener evidencias de validez vinculadas con la estructura interna y estimar la confiabilidad de las medidas obtenidas al aplicar el cuestionario FFMQ de Baer et al. (2006), trabajado desde el modelo Rasch logístico multidimensional de coeficientes aleatorios. Dicho instrumento consta de 39 ítems tipo Likert que se responden mediante una escala de 5 puntos y se estructuran en cinco dimensiones: Observación, Descripción, Actuar con Conciencia, Ausencia de Juicio y Ausencia de Reactividad ante Experiencias Internas. Los análisis se realizaron con la información recogida en una muestra no probabilística accidental de 288 practicantes de yoga que reportaron no encontrarse bajo un tratamiento psicoterapéutico o psicofarmacológico.
\end{abstract}

Palabras clave: mindfulness / FFMQ / Rasch / multidimensional / yoga

\section{ADJUSTMENT OF A MULTIDIMENSIONAL RASCH MODEL TO THE FIVE FACET MINDFULNESS QUESTIONNAIRE (FFMQ) ADMINISTERED TO YOGA PRACTITIONERS}

\begin{abstract}
This research aims to gather evidence on the validity of the internal structure of and estimate the reliability of the measurements from the FFMQ (Baer et al., 2006) using the multidimensional random coefficient multinomial logit model. Such instrument consists of 39 Likert-type items answered by selecting an option from a five-point rating scale on five dimensions: Observing, Describing, Acting with Awareness, Non-Judging and Non-Reactivity to Inner Experience. The analysis was conducted using data collected from an accidental non-probabilistic sample of 288 yoga practitioners who reported not being under a psychotherapeutic or psychopharmacological treatment.
\end{abstract}

Keywords: mindfulness / FFMQ / Rasch / multidimensional / yoga 


\section{INTRODUCCIÓN}

El concepto de conciencia plena proviene principalmente del budismo, donde el estado de estar atento y percatarse de lo que está sucediendo en el momento presente es cultivado activamente (Brown y Ryan, 2003). Por su parte, Kabat-Zinn (2013), uno de los autores que más ha trabajado el tema, la define como la percatación que surge al intencionalmente prestar atención al momento presente sin criticarlo. En ese sentido, no implica un análisis cognitivo, por lo que todas las experiencias percibidas (pensamientos, sentimientos, sensaciones, etcétera) son aceptadas, sin emitir un juicio de valor (Davis y Hayes, 2011). Westen (1999) considera que la consciencia plena abarca la percatación y la atención: la primera hace referencia a un monitoreo constante del ambiente, mientras que la segunda viene a ser el proceso consciente de centrar la percatación, resultando en una alta sensibilidad a un rango limitado de estímulos.

De este modo, el procesamiento de la conciencia plena involucra un estado cognitivo receptivo, en donde la atención se dedica al mero registro de los hechos observados. Cuando se utiliza de esta manera para prolongar ese contacto inicial con el mundo, las capacidades básicas para la percatación y atención permiten al individuo estar presente en la realidad tal y como es, en lugar de reaccionar a ella o procesarla habitualmente mediante filtros conceptuales. En este estado, incluso las reacciones usuales que pueden ocurrir cuando la atención está involucrada (pensamientos, imágenes, verbalizaciones, emociones, etcétera) pueden observarse como parte de la corriente continua de conciencia (Siegel, Germer y Olendzki, 2008).

La conciencia plena permite la inmediatez de un contacto directo con eventos a medida que ocurren, sin la superposición del pensamiento discriminativo, categórico y habitual. Facilita una claridad y frescura que posibilitan respuestas conductuales más flexibles y objetivas (Kabat-Zinn, 2013). Se ha propuesto que esta postura metacognitiva de percatación y aceptación puede alterar la relación del individuo con sus pensamientos y sentimientos al crear un descentramiento de sí mismo y de los significados personales que atribuye a eventos. Esto reduciría la frecuencia y magnitud de estados de ánimo negativos, así como de actitudes disfuncionales (Williams et al., 2012).

Por ello, las intervenciones basadas en consciencia plena, como la reducción del estrés basado en conciencia plena (MBSR por sus siglas en inglés; Kabat-Zinn, 1990) o la terapia cognitiva basada en consciencia plena (MCT por sus siglas en inglés; Segal, Williams y Teasdale, 2013) han ganado una creciente popularidad. Desde estas perspectivas, el entrenamiento en conciencia plena es una intervención psicológica dirigida a lograr que los practicantes mantengan su atención en la experiencia presente, sin un juicio o procesamiento analítico (Brown y Ryan, 2003; Kabat-Zinn, 1982). Se postula que esta postura metacognitiva puede alterar la relación de una persona con sus pensamientos y sentimientos al crear un descentramiento de sí mismo y sus significados 
personales, reduciendo así la magnitud de los efectos de los estados de ánimo negativos y actitudes disfuncionales (Teasdale et al., 2002; Williams et al., 2012).

La evidencia empírica sugiere que este tipo de intervenciones combaten síntomas relacionados con trastornos del ánimo como la depresión y la ansiedad (Kristofersson, 2012); se han reportado mejoras en los síntomas asociados al trastorno obsesivocompulsivo (Hertenstein et al., 2012), efectividad en el manejo de la ira en individuos con trastorno limítrofe de personalidad (Sauer y Baer, 2012), mejoras en los síntomas psicológicos y conductuales asociados al hipotiroidismo (Schulte, 2007) y beneficios para el funcionamiento mental en pacientes con síntomas sin explicación médica (van Ravesteijn et al., 2013). Además, se han encontrado mejoras en la autoestima (Goldin y Gross, 2010), capacidad de memoria en adultos mayores (Lenze et al., 2014) y uso de mejores estrategias de afrontamiento en estudiantes universitarios (Halland et al., 2015).

En general, la investigación sobre los beneficios de estas estrategias de intervención no ha sido muy extensa, pero ha aumentado en años recientes junto con el interés por entender cómo puede ser medida de forma más eficiente (Heeren et al., 2011). En ese sentido, si bien existe una variedad de instrumentos para medir este constructo, Baer et al. (2008) señalan que las diferencias en su contenido y estructura indican una falta de consenso acerca de la conceptualización de la conciencia plena. Con el objetivo de superar estas limitaciones, estos autores integraron ítems de los diferentes cuestionarios para formar cinco factores estructurales (observación, descripción, actuar con conciencia, ausencia de juicio y ausencia de reactividad ante experiencias internas) que resultaron en el FFMQ (Baer, Smith, Hopkins, Krietemeyer y Toney, 2006).

En cuanto a las propiedades psicométricas, Baer et al. (2008) reportaron evidencias de validez vinculadas con la estructura interna, usando cuatro muestras de participantes: meditadores regulares, no meditadores con similitudes demográficas, una muestra general de la comunidad y una muestra de estudiantes. Para ello utilizaron el análisis factorial confirmatorio, postulando un modelo jerárquico en el que los cinco factores son indicadores del factor global conciencia plena. Dichos autores reportaron un buen ajuste al modelo (CFI = .97, TLI = .96, RMSEA = .06 [90 \% Cl: .05 - .08], SRMR = .05), intercorrelaciones de las cinco facetas que oscilaron entre .32 y $.56(p<.01)$; cargas de los factores en el constructo general que oscilan entre .53 y .84 , y finalmente, coeficientes alfa de Cronbach para las puntuaciones obtenidas en cada factor, que oscilaron entre .67 y .92 para las diferentes muestras.

Dado el buen soporte psicométrico, este instrumento ha sido adaptado a diferentes poblaciones e idiomas, como el danés (Veehof, 2011), el italiano (Giovannini et al., 2014) y el chino (Deng et al., 2011). Por su parte, Schmidt y Vinet (2015) trabajan una versión en castellano con estudiantes universitarios chilenos y Papi (2017) analiza una versión en castellano con practicantes de yoga en Lima Metropolitana. 
Si bien ya existe una versión en castellano trabajada en Lima Metropolitana, ha sido analizada desde una perspectiva factorialista, la cual tiene como deficiencia no producir verdaderas medidas de intervalo a partir de la aplicación de un instrumento psicométrico (Bond y Fox, 2015; Schumacker y Linacre, 1996). Este problema es superado por los modelos Rasch, que se basan en presentar una versión probabilística de los axiomas de medición conjunta de Luce y Tuckey (Borsboom y Scholten, 2008; Fisher, 1994; Fisher y Wright, 1994).

Específicamente, en el presente trabajo de investigación se plantea aplicar el modelo logístico multidimensional de coeficientes aleatorios (MRCLM, por sus siglas en inglés), que puede ser ajustado tanto a ítems dicotómicos como polinómicos, considerando la relación entre la localización de una persona en el espacio multidimensional latente y la probabilidad de responder de determinada manera a un ítem (Adams, Wilson y Wang, 1997). Entre las ventajas de este modelo se puede destacar su capacidad para reportar las características de los ítems y de las personas en la misma métrica, usando una escala de intervalo y el permitir la estimación de la confiabilidad considerando la estructura multidimensional de los datos (Briggs y Wilson, 2003; Adams et al., 1997, Wang, Chen y Cheng, 2004).

Es por ello que los objetivos planteados para la presente investigación son: obtener evidencias de validez vinculadas con la estructura interna y estimar la confiabilidad de las medidas obtenidas al aplicar el cuestionario FFMQ, considerando su estructura multidimensional. Todo ello trabajado desde el modelo Rasch logístico multidimensional de coeficientes aleatorios (Adams et al., 1997).

\section{MÉTODO}

\section{Participantes}

Se trabajó con una muestra no probabilística accidental (Howitt y Cramer, 2011) de 288 participantes que reportaron practicar yoga como mínimo una vez por semana y no encontrarse bajo un tratamiento psicoterapéutico o psicofarmacológico.

En cuanto a las características de los participantes, 82 \% tienen educación universitaria; 83 \% fueron mujeres y el resto varones. La edad promedio fue de 36 años, con una desviación estándar de 12 y asimetría igual a 0,9. Finalmente, se puede señalar que en promedio tienen tres años practicando yoga $(D E=5, A s=4,4)$.

\section{Instrumentos}

Todos los participantes completaron una ficha sociodemográfica en la que se recogió información sobre su edad, sexo, distrito de residencia y grado de instrucción. Además, 
se les pidió especificar si se encontraban bajo un tratamiento psicofarmacológico o psicoterapéutico. Con respecto a la práctica del yoga, en caso de practicar por lo menos una vez a la semana, se solicitó detallar el tiempo de práctica y la frecuencia actual con la que lo hacen.

El instrumento principal de esta investigación fue la versión traducida al español del Cuestionario de las Cinco Faceta de Mindfulness (Five Facet Mindfulness Questionnaire [FFMQ]) (Baer et al., 2006), trabajada por Loret de Mola (2009). Consta de 39 ítems tipo Likert con un rango de respuesta del 1 al 5, siendo 1 es Nunca o muy rara vez cierto y 5 Muy a menudo o siempre cierto. Los ítems están organizados en cinco factores, los cuales se definen que la siguiente manera (Baer et al., 2006; Baer et al., 2008):

- Observación: notar y atender tanto a las experiencias internas como externas, incluyendo sensaciones corporales, cogniciones, emociones, sonidos, olores y visiones. Incluye los ítems 1, 6, 11, 15, 20, 26, 31 y 36.

- Descripción: capacidad para nombrar y describir experiencias internas con palabras. Incluye los ítems 2, 7, 12, 16, 22, 27, 32 y 37.

- Actuar con conciencia: centrar la atención de manera consciente y constante a cada acción que la persona realiza. Incluye los ítems 5, 8, 13, 18, 23, 28, 34 y 38 .

- Ausencia de juicio: vivir las experiencias internas (pensamientos y sentimientos) del momento presente sin someterlas a una valoración. Así, estas se aceptan tal y como son, hasta llegar a concientizarlas. Incluye los ítems 3, 10, 14, 17, 25 , 30,35 у 39 .

- Ausencia de reactividad ante experiencias internas: tendencias a permitir que sentimientos y emociones se desarrollen sin control del individuo y sin que este se deje llevar por aquellos. Incluye los ítems 4, 9, 19, 21, 24, 29 y 33.

Para estimar las evidencias de validez vinculadas con la estructura interna del FFMQ, Papi (2017) realizó un análisis factorial exploratorio (AFE) sobre la matriz de correlaciones policóricas, dado que las respuestas a los ítems constituyen una escala politómica ordinal (Burga, 2006). El método de extracción empleado fue el ULS, que ha demostrado buenos resultados recuperando soluciones factoriales (Tucker y MacCallum, 1997; Lorenzo-Seva y Ferrando, 2015). Dado que no se tuvieron evidencias para anticipar independencia entre los factores (Baer et al., 2008; Williams, Dalgleish, Karl y Kuyken, 2014), se utilizó la rotación oblicua promin para mejorar la interpretabilidad de los factores (Lorenzo-Seva, 2013).

Papi (2017) reporta que la información contenida en la matriz de correlaciones fue adecuada para realizar un análisis factorial $(\mathrm{KMO}=.86, \mathrm{X2}(703)=5534.20, \mathrm{p}<.001)$. Como resultado del dicho análisis se observó que casi todos los ítems, salvo el 36 , 
presentaron cargas superiores a .40 en el factor al cual pertenecían desde un punto de vista teórico, lo que explica el 52 \% de la varianza con los 38 ítems mantenidos luego de la factorización.

En cuanto a la confiabilidad de las puntuaciones, considerando el nivel de medición de los ítems que conforman el test, se utilizó el coeficiente alfa ordinal (Gadermann, Guhn y Zumbo, 2012). Los análisis realizados por Papi (2017) muestran que los coeficientes estimados para las puntuaciones obtenidas a partir de los ítems que corresponden a cada uno de los factores fueron adecuados: observación, .85; descripción, .88; actuar con conciencia, ausencia de juicio, .86; ausencia de reactividad ante experiencias internas, .75.

\section{Procedimiento}

Los datos fueron recogidos en el contexto de la investigación realizada por Papi (2017), que buscaba analizar el efecto mediacional de la conciencia plena entre la práctica del yoga y la rumiación en adultos de Lima Metropolitana. Para ello se contactó a cinco instituciones de práctica de yoga, solicitando la autorización formal para la aplicación de los instrumentos. Se expusieron los fines académicos y condiciones de confidencialidad de la investigación. Se aseguró, además, que bajo ningún motivo se utilizaría el nombre de las instituciones, así como tampoco el de los individuos.

Se buscó la participación voluntaria de adultos, teniendo como requisito haber leído, comprendido y firmado el consentimiento informado antes de responder a las escalas. Se dieron las instrucciones para cada instrumento de forma individual a cada participante, quedando pendiente a cualquier duda que pudiera surgir durante la resolución de las escalas. Se evitó mencionar las variables a medir para evitar un posible sesgo en las respuestas de los participantes (ante sus preguntas, se indicó que se buscaba características de personas). Los instrumentos fueron aplicados antes y después de cada clase, siempre y cuando los individuos dispusieran de tiempo suficiente (aproximadamente quince minutos).

\section{RESULTADOS}

Todos los análisis psicométricos fueron realizados mediante el lenguaje y programa de análisis estadístico R (https://cran.r-project.org). Específicamente se utilizó el paquete TAM v.2.12-18 (Robitzsch, Kiefer y Wu, 2018), que permite, entre otras cosas, ajustar el modelo generalizado logístico multinomial de coeficientes aleatorios que, dependiendo de los parámetros y restricciones dadas a las matrices de diseño y calificación, puede ser ajustado a ítems dicotómicos o polinómicos, datos unidimensionales o multidimensionales (Wang, Wilson y Adams, 1997). 
El ajuste de los ítems según el modelo psicométrico utilizado fue valorado mediante los índices infit y outfit, cuyos valores recomendables, en el caso politómico, fluctúan entre 0,6 y 1,4 (Wrigth y Linacre, 1996). Todos los ítems considerados, menos el 38, mostraron valores dentro de los parámetros aceptables (ver tabla 1), por lo cual este fue eliminado de los análisis. Además, todas las categorías de la escala de valoración han resultado ser valores modales, lo que produce umbrales Rasch-Andrich ordenados cuyos valores fueron: $-1,654,-0,778,0,433$ y 2,009 .

Tabla 1

Medidas de localización, error estándar y ajuste de los ítems

\begin{tabular}{llllllllll}
\hline ítem & medida & error & infit & outfit & ítem & medida & error & infit & outfit \\
\hline 01 & $-0,360$ & 0,072 & 1,14 & 1,15 & C23_I & $-1,525$ & 0,082 & 1,13 & 1,07 \\
06 & $-0,371$ & 0,072 & 1,27 & 1,28 & C28_I & $-0,645$ & 0,073 & 0,84 & 0,86 \\
015 & $-0,682$ & 0,074 & 1,01 & 0,97 & C34_I & $-1,076$ & 0,076 & 0,89 & 0,89 \\
020 & $-0,617$ & 0,073 & 1,20 & 1,19 & C38_I & $-0,927$ & 0,075 & 0,94 & 0,95 \\
026 & $-1,268$ & 0,079 & 0,98 & 0,95 & J3_I & $-0,420$ & 0,072 & 1,04 & 1,07 \\
031 & $-1,389$ & 0,081 & 1,28 & 1,21 & J10_I & $-0,102$ & 0,070 & 1,12 & 1,20 \\
036 & $-0,731$ & 0,074 & 1,04 & 1,04 & J14_I & $-1,537$ & 0,082 & 1,02 & 1,01 \\
D2 & $-0,753$ & 0,074 & 0,79 & 0,81 & J17_I & $-0,364$ & 0,071 & 1,06 & 1,08 \\
D7 & $-1,143$ & 0,078 & 0,91 & 0,90 & J25_I & $-0,493$ & 0,072 & 1,12 & 1,14 \\
D12_I & $-1,167$ & 0,078 & 1,03 & 1,03 & J30_I & $-1,125$ & 0,077 & 1,03 & 0,98 \\
D16_I & $-1,155$ & 0,078 & 0,94 & 0,90 & J35_I & $-0,787$ & 0,074 & 0,93 & 0,97 \\
D22_I & $-1,161$ & 0,078 & 0,98 & 0,97 & J39_I & $-0,652$ & 0,073 & 1,26 & 1,26 \\
D27 & $-0,502$ & 0,072 & 0,92 & 0,89 & R4 & $-0,171$ & 0,069 & 0,89 & 0,89 \\
D32 & $-0,440$ & 0,072 & 1,06 & 1,04 & R9 & $-0,247$ & 0,069 & 0,76 & 0,76 \\
D37 & $-0,672$ & 0,073 & 0,77 & 0,76 & R19 & $-0,054$ & 0,068 & 1,06 & 1,07 \\
C5_I & $-0,098$ & 0,069 & 0,98 & 0,98 & R21 & $-0,478$ & 0,070 & 0,84 & 0,83 \\
C8_I & $-0,795$ & 0,074 & 0,82 & 0,83 & R24 & $-0,333$ & 0,069 & 1,08 & 1,10 \\
C13_I & $-0,353$ & 0,071 & 093 & 0,92 & R29 & 0,174 & 0,067 & 0,88 & 0,89 \\
C18_I & $-0,939$ & 0,075 & 1,01 & 1,01 & R33 & $-0,419$ & 0,070 & 0,75 & 0,75 \\
\hline
\end{tabular}

En la tabla 2 se muestran las correlaciones estimadas entre las medidas obtenidas para cada una de las dimensiones, las cuales fluctúan entre -.046 y .625. 
Tabla 2

Correlaciones entre las medidas de las cinco dimensiones del FFMQ

\begin{tabular}{lccccc}
\hline Factor & 1 & 2 & 3 & 4 & 5 \\
\hline 1. Observación & - & & & & \\
2. Descripción & .379 & - & & & \\
3. Actuar con conciencia & .136 & .450 & - & - & \\
4. Ausencia de juicio & -.046 & .303 & .543 & .043 & - \\
5. Ausencia de reactividad & .598 & .627 & .172 & & \\
\hline
\end{tabular}

Finalmente, la tabla 3 muestra la confiabilidad de las medidas estimadas mediante el modelo multidimensional ajustado, el cual considera la estructura de correlaciones existente entre las dimensiones (Briggs y Wilson, 2003).

Tabla 3

Confiabilidad de las medidas derivadas de los ítems que conforman cada una de las cinco dimensiones del FFMQ, estimadas con el método WLE

\begin{tabular}{lc}
\hline Dimensión & Coeficiente \\
\hline Observación & .832 \\
Descripción & .847 \\
Actuar con conciencia & .830 \\
Ausencia de juicio & .855 \\
Ausencia de reactividad & .790 \\
\hline
\end{tabular}

\section{DISCUSIÓN}

Debe señalarse que se cumplieron los objetivos que sirvieron como guía en la presente investigación: obtener evidencias de validez vinculadas con la estructura interna y estimar la confiabilidad de las medidas obtenidas al aplicar el cuestionario FFMQ, trabajado desde el modelo Rasch logístico multidimensional de coeficientes aleatorios (Adams et al., 1997).

Una ventaja de contar con estos modelos multidimensionales es que esta situación responde de forma directa a las demandas reales que se desprenden de la práctica evaluativa, pues muchas veces se necesita más que un resumen unidimensional del rasgo de las personas analizadas, reconociendo explícitamente la estructura planteada por quienes construyen un test y proveen estimaciones de la relación entre las dimensiones latentes corregidas por los errores de medición (Adams, Wilson y Wang, 1997). Además, tienen la ventaja de lograr medidas confiables con pocos ítems, en especial cuando hay varias dimensiones y correlaciones altas entre ellas (Wang et al., 2004). Finalmente, Shih, Chang y Cheng (2013) consideran que otra ventaja del MRCML es que 
puede ser comparado, en cuanto a su adecuación, con un modelo unidimensional u otros modelos, usando el índice de confiabilidad y el criterio de información de Akaike.

En cuanto a los resultados empíricos, la estructura factorial obtenida a partir del AFE realizado para el cuestionario FFMQ fue consistente con el sustento teórico y con resultados de investigaciones previas (Baer et al., 2008; Papi, 2017). Particularmente, en muestras con experiencia en meditación, un gran número de estudios han confirmado un modelo jerárquico de cinco factores, en el que las cinco subescalas pueden ser entendidas como elementos de un constructo principal: conciencia plena (Baer, 2016).

Desde un punto de vista aplicado, la importancia de la estructura multidimensional del FFMQ radica en el beneficio que supone conocer las relaciones específicas entre una dimensión y otros constructos, ya sea para potenciar o disminuir las influencias de este último. Por ejemplo, a partir de los resultados de su investigación, Peters et al. (2015) recomiendan cultivar las dimensiones de ausencia de juicio y ausencia de reactividad ante experiencias internas para tener un mejor resultado en la reducción del comportamiento agresivo. Por otro lado, Baer et al. (2008) señalan que la dimensión observación, a pesar de ser un elemento central de la conciencia plena, parece tener efectos adaptativos si se ha tenido entrenamiento en meditación, pero efectos desadaptativos en la población general, teniendo una correlación positiva y moderada con variables como supresión del pensamiento, disociación y evitación de la experiencia.

Sin embargo, hay que tener en cuenta que la estructura del FFMQ no siempre ha sido replicada. Por ejemplo, el trabajo de Tran et al. (2014) sugiere que los cinco factores no son del todo replicables y que se encuentra especial dificultad referida al factor de observación por presentar asociaciones significativas con el constructo de rumiación. Asimismo, sostienen que las puntuaciones derivadas de los ítems del FFMQ muestran diferentes propiedades psicométricas en meditadores y en no meditadores; por ejemplo, la dimensión ausencia de reactividad ante experiencias internas muestra propiedades de medida débiles solo en muestras de no meditadores. Asimismo, en muestras sin experiencia en meditación, la dimensión observación evidencia una relación inconsistente con las otras dimensiones, además de una carga factorial en el constructo principal de conciencia plena que no es estadísticamente significativa (Baer, 2016; Tran et al., 2014, Heeren et al., 2011).

En el presente estudio se trabajó con una muestra de practicantes de yoga. Entendiendo la conciencia plena como parte del yoga (Uebelacker et al., 2010), es posible que la muestra de estudio haya estado compuesta predominantemente por individuos con experiencia en meditación y que, por tanto, los resultados obtenidos encajen dentro de todas las investigaciones que han reportado una estructura de cinco factores con una muestra de meditadores. Esto explicaría por qué el factor de observación no supuso dificultades significativas como las señaladas en el párrafo anterior. 
Tal y como se señaló en la sección de resultados, se eliminó el ítem 38 "Me encuentro a mí mismo(a) haciendo cosas sin prestarles atención", por no contar con indicadores adecuados de ajuste al modelo. Es posible que esto ocurriera por una dificultad al entender el enunciado; particularmente se cree que fue complejo comprender el sentido de "Me encuentro a mí mismo(a)", lo que dio como resultado un ítem poco claro. Tal vez una mejor redacción podría ser "Me doy cuenta de que hago cosas sin prestarles atención". Sin embargo, cualquier modificación debe ser probada empíricamente antes de poder incorporarla en una nueva versión del FFMQ.

Pasando a comentar los resultados referidos a la confiabilidad estimada para las medidas derivadas de aplicar el FFMQ, los coeficientes no son radicalmente diferentes de los reportados por Papi (2017) y los trabajados por Loret de Mola (2009) con una muestra de meditadores y no meditadores adultos con educación superior de Lima Metropolitana: observación (.77), descripción (.88), actuar con conciencia (.86), ausencia de juicio (.86) y ausencia de reactividad (.78).

En cuanto a los valores mínimos aceptables de los coeficientes de confiabilidad, existe mucha discusión. Por ejemplo, Charter (2003) ha realizado una revisión de numerosas investigaciones donde se proponen diferentes niveles mínimos. En ese estudio encontró bastante variabilidad al observar valores propuestos con los diversos métodos para obtener la confiabilidad, que oscilan entre .60 y .95 . A pesar de esas discrepancias, y tomando como estándar mínimo aceptable .70, los valores obtenidos en la presente investigación resultan ser suficientes, pues la mayoría se encuentra sobre .80 . Esto implica que se está estimando la cantidad del rasgo latente de cada persona con un error de medición que permite tomar decisiones a partir de los resultados obtenidos en el proceso (Brennan, 2001).

Considerando todo lo expuesto hasta el momento, se puede concluir que resulta válido interpretar los resultados obtenidos a partir del FFMQ basándose en un modelo multidimensional. En general, hay un ajuste adecuado al modelo de cinco factores; 38 de los 39 ítems muestran valores infit y outfit en el rango de 0,6 a 1,4. Además, las correlaciones entre las medidas obtenidas en las cinco dimensiones varían entre -.05 y .63, y finalmente, la confiabilidad de las medidas fluctúa entre .79 y .86 .

Dadas las propiedades psicométricas, se recomienda utilizar el instrumento de medición desde una perspectiva multidimensional, utilizando el modelo Rasch logístico multidimensional de coeficientes aleatorios (Wang et al., 1997), pues tiene como ventaja producir verdaderas medidas en nivel de intervalo (Bond y Fox, 2015). Sin embargo, no debe descartarse la posibilidad de probar otros modelos en futuras investigaciones, como el propuesto por Brandt (2008), que implica una estructura jerárquica de los datos, aunque con varias restricciones con el fin de lograr la convergencia. Además, se debe analizar la invarianza de la estructura multidimensional propuesta, así como 
la de los parámetros del modelo, en especial si se busca realizar comparaciones entre grupos de personas.

\section{REFERENCIAS}

Alarcón, R. (2008). Métodos y diseños de investigación del comportamiento. Lima: Universidad Ricardo Palma.

Bejarano, M. Galván, F. y López, B. (2014). Pensamiento crítico y motivación hacia el pensamiento crítico en estudiantes de Psicología. Aletheia, 6(2), 202-223. Recuperado de http://aletheia.cinde.org.co/index.php/ALETHEIA/article/view/218

Boisvert, J. (2004). La formación del pensamiento crítico. México, D. F.: Fondo de Cultura Económica.

Cohen, J. (1988). Statistical power analysis for the behavioral sciences. Hillsdale: Lawrence Earlbaum Associates.

Çubukcu, Z. (2006). Critical thinking dispositions of the Turkish teacher candidates. The Turkish Online Journal of Educational Technology, 5(4), 22-36. Recuperado de www.tojet.net/volumes/v5i4.pd

Delgado, A. E., Escurra, L. M. y Torres, W. (2006). La medición en Psicología y Educación: teoría y aplicaciones. Lima: Hozlo S.R.L.

Dewey, J. (1933). How we think. Boston: D. C. Heath. Recuperado de https://ia801406. us.archive.org/17/items/howwethink000838mbp/howwethink000838mbp.pdf

Ennis, R. H. (1986). A taxonomy of critical thinking dispositions and abilities. In J. B. Baron y R. J. Sternberg (eds.), Teaching thinking skills. New York: Freeman.

Ennis, R. H. (2011). The nature of critical thinking: An outline of critical thinking dispositions and abilities. Recuperado de http://faculty.education.illinois.edu/rhennis/documents/ TheNatureofCriticalThinking_51711_000.pdf

Escurra, L. y Delgado, A. (2008a). Construcción de la escala de disposición hacia el pensamiento crítico utilizando el modelo de Samejima en alumnos universitarios de la ciudad de Lima. Teoría e Investigación en Psicología, 18(1), 41-72.

Escurra, M. y Delgado, A. (2008b). Relación entre disposición hacia el pensamiento crítico y estilos de pensamiento en alumnos universitarios de Lima metropolitana. Persona. Revista de la Facultad de Psicología. Universidad de Lima (11), 143-175.

Facione, P. (1990). The Delphi Report, Critical Thinking: A Statement of Expert Consensus for Purposes of Educational Assessment and instruction. Millbrae: The California Academic Press.

Facione, P. A., Giancarlo, C. A., Facione, N. C. y Gainen, J. (1995). The disposition toward Critical Thinking. Journal of General Education, 44(1), 1-25. Recuperado de https:// www.insightassessment.com/content/.../file/Disposition_to_CT_1995_JGE.pdf 
Facione, P. y Facione, N. (1992). The California Critical Thinking Dispossitions Inventory (CCTDI); and the CCTDI Test manual. Millbrae: California Academic Press.

Facione, P. A., Facione N. C. y Giancarlo C. A. (1997). Professional judgement and the disposition toward critical thinking. Millbrae: California Academic Press.

Facione, P. A., Facione, N. C., Giancarlo, C. A. y Gainen, J. (2000). The disposition toward Critical Thinking: Its Character, Measurement, and Relationship to Critical Skill. Informal Logic, 20(1), 61-84. ojs.uwindsor.ca/ojs/leddy/index.php/informal_logic/ article/download/2254/1698

García, I., Graterol, V. y Triviño, A. (2014). Potencialización del pensamiento: ser estratégico por medio del juego. Trabajo de grado para optar el título de Licenciatura en Pedagogía Infantil. Chía: Universidad de la Sabana. Recuperado de http:// intellectum.unisabana.edu.co/handle/10818/11199

León, F. (2014). Sobre el pensamiento reflexivo, también llamado pensamiento crítico. Propósitos y Representaciones, 2(1), 161-214. http://dx.doi.org/10.20511/pyr2014. v2n1.56

López, G. (2012). Pensamiento crítico en el aula. Docencia e Investigación (22), 41-60.

Perea, L. (2017). Disposición hacia el pensamiento crítico y su relación con el rendimiento académico en estudiantes del curso de Metodología de la Investigación de una Universidad Privada de Lima Metropolitana. Tesis para optar el grado académico de Maestro en Educación con mención en Docencia e Investigación en Educación Superior. Lima: Universidad Peruana Cayetano Heredia. Recuperado de http:// repositorio.upch.edu.pe/bitstream/handle/upch/945/Disposicion_Perea\%20 Romero\%2C\%20Lizette.pdf?sequence=3\&isAllowed $=y$

Sánchez, H. y Reyes, C. (2015). Metodología y diseños en la investigación científica. Lima: Business Support Aneth S.R.L.

Siegel, H. (1990). Critical Thinking as an Educational Ideal. New York: Routledge.

Sierra, J., Carpintero, E. y Pérez, L. (2010). Pensamiento crítico y capacidad intelectual. FAISCA, 15(17), 98-110. Recuperado de http://revistas.ucm.es/index.php/FAIS/ article/view/8505

Torres, N. (2011). Influencia de las disposiciones en el desarrollo del pensamiento crítico y el aprendizaje de las Ciencias Naturales. Educar em Revista, Curitiba, Brasil lon line], 41, 247-259. Recuperado de www.scielo.br/pdf/er/n41/16.pd

Velásquez, M. y Figueroa, H. (2010). Desarrollo del pensamiento crítico en estudiantes de las carreras universitarias de mayor demanda de El Salvador. Panorama, 6(10), 7-20. Recuperado de https://dialnet.unirioja 


\section{APÉNDICE 1 - INSTRUMENTO UTILIZADO}

\section{Recuerde que no hay respuestas buenas ni malas, pero trate de responder lo más honestamente posible con respecto a cómo habitualmente piensa, se siente y comporta.}

Por favor, califique cada una de las siguientes afirmaciones según la escala propuesta. Marque con una " $X$ " en la frecuencia que describe de la mejor manera su opinión sobre cuán cierta es cada afirmación para usted.

$1=$ Nunca 0 muy rara vez cierto

$2=$ Rara vez cierto

$3=$ Algunas veces cierto

$4=\mathrm{A}$ menudo cierto

$5=$ Muy a menudo o siempre cierto

1 Cuando camino, me doy cuenta deliberadamente de las sensaciones de mi $1 \begin{array}{lllll}1 & 2 & 3 & 4 & 5\end{array}$ cuerpo en movimiento.

2 Soy bueno(a) en encontrar palabras para describir mis sentimientos. $\quad 1 \quad 1 \quad 2 \quad 3 \quad 4 \quad 5$

3 Me critico por tener emociones irracionales o inapropiadas. $\quad 1 \quad 2 \quad 3 \quad 4 \quad 5$

4 Percibo mis sentimientos y emociones sin tener que reaccionar ante ellos. $\quad \begin{array}{llllll}1 & 2 & 3 & 4 & 5\end{array}$

5 Cuando hago algo, mi mente tiende a divagar y me distraigo fácilmente. $\quad \begin{array}{lllllll}2 & 3 & 4 & 5\end{array}$

6 Cuando me baño o tomo una ducha, me mantengo alerta a las sensaciones del $1123 \quad 3 \quad 4 \quad 5$ agua sobre mi cuerpo.

$7 \quad$ Puedo fácilmente poner en palabras mis creencias, opiniones y expectativas. $\quad \begin{array}{llllll}1 & 2 & 3 & 4 & 5\end{array}$

8 No presto atención a lo que hago por estar soñando despierto(a), andar $\begin{array}{llllll}1 & 2 & 3 & 4 & 5\end{array}$ preocupado(a), o distraído(a) de alguna otra manera.

9 Observo mis sentimientos sin perderme en ellos. $\quad 1 \quad 2 \quad 3 \quad 4 \quad 5$

10 Me digo a mí mismo(a) que no me debería estar sintiendo como me estoy $11 \quad 2 \quad 3 \quad 4 \quad 5$ sintiendo.

11 Me doy cuenta de cómo alimentos y bebidas afectan mis pensamientos, $1 \begin{array}{lllll} & 2 & 3 & 4 & 5\end{array}$ sensaciones corporales y emociones.

12 Me es difícil encontrar las palabras para describir lo que estoy pensando. $\quad \begin{array}{llllll}2 & 2 & 3 & 4 & 5\end{array}$

13 Me distraigo fácilmente. $\quad 1 \quad 2 \quad 3 \quad 4 \quad 5$

14 Creo que algunos de mis pensamientos no son normales o son malos y que no $\quad 1 \quad 2 \quad 3 \quad 4 \quad 5$ debería pensar de tal manera.

15 Presto atención a sensaciones, como el viento entre mi cabello o el sol sobre $1124 \quad 3 \quad 4 \quad 5$ mi rostro.

16 Tengo problemas para pensar en las palabras indicadas que expresen cómo $11 \quad 2 \quad 3 \quad 4 \quad 5$ me siento con respecto a las cosas.

17 Hago juicios sobre si mis pensamientos son buenos o malos. $\quad 1 \quad 2 \quad 3 \quad 4 \quad 5$ 
18 Se me hace difícil mantenerme enfocado(a) en lo que ocurre en el presente. $\quad \begin{array}{llllll}1 & 2 & 3 & 4 & 5\end{array}$

19 Cuando experimento pensamientos o imágenes mentales aflictivas, me $1124 \quad 3 \quad 4 \quad 5$ "detengo" y soy consciente del pensamiento o imagen sin dejar que estos se apoderen de mí.

20 Presto atención a sonidos, como los de las manecillas de un reloj, el cantar de $\quad \begin{array}{llllll}1 & 2 & 3 & 4 & 5\end{array}$ los pájaros o el pasar de los autos.

21 En situaciones difíciles soy capaz de hacer una pausa sin tener que reaccionar $\quad \begin{array}{llllll}2 & 2 & 3 & 4 & 5\end{array}$ inmediatamente.

22 Cuando tengo una sensación en mi cuerpo, me es difícil describirla pues no $\quad 1 \quad 2 \quad 3 \quad 4 \quad 5$ puedo encontrar las palabras indicadas.

23 Parece que actúo en "piloto automático", sin mayor consciencia de lo que estoy $1 \begin{array}{lllll}1 & 2 & 3 & 4 & 5\end{array}$ haciendo.

24 Cuando tengo pensamiento o imágenes mentales aflictivas, recobro la calma $1124 \quad 3 \quad 4 \quad 5$ poco después.

25 Me digo a mí mismo(a) que no debería estar pensando como estoy pensando. $\quad \begin{array}{llllll}1 & 2 & 3 & 4 & 5\end{array}$

26 Percibo los olores y aromas de las cosas. $\quad 1 \quad 2 \quad 3 \quad 4 \quad 5$

27 Incluso cuando me siento terriblemente alterado(a), soy capaz de encontrar la $1 \begin{array}{llllll}1 & 2 & 3 & 4 & 5\end{array}$ manera de ponerlo en palabras.

28 Me apresuro entre una y otra actividad sin estar muy atento a cada una de ellas. $1 \begin{array}{lllll}1 & 2 & 4 & 4 & 5\end{array}$

29 Cuando tengo pensamientos o imágenes mentales aflictivas, soy capaz de $\quad \begin{array}{lllllll}1 & 2 & 3 & 4 & 5\end{array}$ observarlas sin reaccionar.

30 Pienso que algunas de mis emociones son malas o inapropiadas y que no $\quad 1 \quad 2 \quad \begin{array}{lllll}3 & 4 & 5\end{array}$ debería sentirlas.

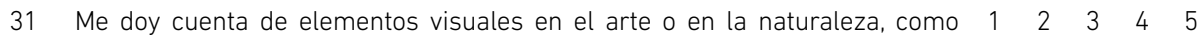
colores, formas, texturas y patrones de luz y sombra.

32 Mi tendencia natural es la de colocar mis experiencias en palabras. $\quad 1 \quad 1 \quad 2 \quad 3 \quad 4 \quad 5$

33 Cuando tengo pensamientos o imágenes aflictivas, puedo reconocerlas como $1124 \quad 3 \quad 4 \quad 5$ tales y dejarlas ir.

34 Realizo deberes o tareas de manera automática sin estar consciente de lo que $\quad \begin{array}{lllll}1 & 2 & 3 & 4 & 5\end{array}$ estoy haciendo.

35 Cuando tengo pensamientos o imágenes mentales aflictivas, me juzgo a mí $1 \begin{array}{lllll}1 & 2 & 3 & 4 & 5\end{array}$ mismo(a) como bueno(a) o malo(a), dependiendo del tipo de pensamiento o imagen mental.

36 Presto atención a cómo mis emociones afectan mis pensamientos y $11 \quad 2 \quad 3 \quad 4 \quad 5$ comportamiento.

37 Usualmente soy capaz de describir en detalle cómo me siento en un momento $\quad 1 \quad 2 \quad 3 \quad 4 \quad 5$ determinado.

38 Me encuentro a mí mismo(a) haciendo cosas sin prestarles atención.

39 Me desapruebo cuando tengo ideas irracionales.

$\begin{array}{lllll}1 & 2 & 3 & 4 & 5\end{array}$ 